\title{
Ensaio sobre diversidade historiográfica: como escrever (e reconhecer) histórias dos sertões a partir de novas e "velhas" epistemologias
}

\author{
Essay on historiographical diversity: how to write (and recognize) histories of the \\ sertões from new and old epistemologies \\ Evandro dos Santos \\ https://orcid.org/0000-0003-2844-4810 \\ Universidade Federal do Rio Grande do Norte
}

\begin{abstract}
Resumo: O presente artigo, escrito na forma de ensaio, discute questões teóricas e historiográficas relativas à proposta de se estabelecer a História dos Sertões como uma área específica de estudos, concebida por meio de um diálogo aberto e crítico com as demais perspectivas que tematizaram os sertões nos diferentes campos de conhecimento das Humanidades ao longo do tempo, no Brasil e no exterior. Considerando a necessária atenção à pluralidade histórica e semântica do conceito de "sertão" e seus correlatos em idiomas estrangeiros, o artigo estuda a questão do impacto das formas limitadas de história possíveis diante da imposição de um ponto de vista europeu. $\mathrm{O}$ artigo propõe um breve encontro entre tal ponto de vista (denominado como eurocentrismo) e as proposições de alguns estudiosos ligados aos chamados estudos pós-coloniais e estudos subalternos e pondera sobre a possibilidade de uma área de investigação dedicada à história e historiografia dos sertões organizada através da sistematização dos estudos dispersos sobre o assunto e, sobretudo, do trabalho com o conceito de sertão como ferramenta para a construção de historiografias brasileiras e americanas mais diversas e plurais. De modo geral, a pesquisa procura examinar as dimensões políticas, sociais e intelectuais de um conceito que se articula aos principais debates que compõem o âmbito historiográfico contemporâneo no que diz respeito, por exemplo, às relações entre natureza e cultura, à problemática das chamadas novas e "velhas" espacialidades (o nacional, o regional, o global etc.) e à colonialidade do poder.
\end{abstract} Palavras-chave: História dos sertões. Estudos pós-coloniais. Historiografia.

Abstract: This article, written as an essay, discusses theoretical and historiographical matters related to the proposal of establishing the History of the Sertões as a specific area of study, conceived through an open and critical dialogue with the other perspectives that have thematized the sertões in different fields of knowledge of the humanities over time, in Brazil and abroad. Considering the necessary attention to the historical and semantic plurality of the concept of "sertão" and its correlates in foreign languages, the article examines the impact of the limited forms of possible history in face of the imposition of a European point of view. The article proposes a brief encounter between this point of view (called Eurocentrism) and the propositions of some scholars linked to the so-called postcolonial studies and subaltern studies and it ponders the possibility of an area of investigation dedicated to the history and historiography of the sertões, organized through the systematization of the scattered studies on the subject and, above all, through the work with the concept of sertão as a tool for the construction of more diverse and plural Brazilian and American historiographies. In general, the research seeks to examine the political, social and intellectual dimensions of a concept that articulates with the main debates that build the contemporary historiographic scope,

Esta obra está licenciada sob uma Creative Commons - Atribuição 4.0 Internacional 
regarding, for example, the relations between nature and culture, the problematic of the so-called new and "old" spatialities (national, regional, global etc.) and the coloniality of power.

Keywords: History of the sertões. Postcolonial studies. Historiography.

"Não se olhou, porém, para o ensinamento histórico.

É que se preestabelecera a vitória inevitável sobre a rebeldia sertaneja insignificante."

Euclides da Cunha, Os Sertões

\section{A história que chamamos de "nossa" como ensaio}

A história da historiografia brasileira narra, de maneira geral, o percurso de produção do conhecimento histórico como disciplina, desde, sobremaneira, o século XIX e o registro de independência política frente a Portugal, com raras críticas em contrário. ${ }^{1}$ Há, portanto, certa ideia de que a escrita da história se tornou minimamente viável apenas após a liberação política no que tangia à anterior unidade entre o Brasil colonial e a metrópole lusitana. Entretanto, a própria ideia de uma escrita da história estava estritamente condicionada ao pensamento e aos projetos políticos europeus, particularmente, às construções nacionalistas (GUIMARÃES, 2003). Neste sentido, no âmbito de um regime de historicidade futurista, os passados dos países americanos (o fenômeno não atingia apenas o Brasil) eram forçosamente encaixados na linha do tempo europeia, no mais das vezes, apreendidos como atrasados em relação à marcha do homem branco civilizado (HARTOG, 2013, p. 37-41). Tais padrões, impostos ao passado e ao futuro, não permitiam grandes inovações temáticas ou estilísticas e, comumente, propunham o enquadramento supostamente universal das práticas de pesquisa e divulgação da história.

No entanto, a historiografia ocupava, naquele contexto do mundo ocidental, o lugar que, até meados do século XVIII, fora da filosofia política (ARENDT, 2003, p. 110121). Se antes havia estudos, tratados, obras de referência que especulavam acerca dos projetos das monarquias europeias, agora eram os textos de história que, direta ou indiretamente, apontavam alguns rumos para os Estados e seus povos. Um dos conceitos políticos fundamentais da modernidade, isto é, o de liberdade, então pautava o discurso dos letrados que produziam a história, sem, contudo, escapar à regra nacionalista europeia e seu conjunto de referências. A inconformidade entre o modelo europeu e as experiências coloniais criava significativa dificuldade para a escrita de histórias propriamente americanas, muitas vezes vindo a significar limites à escrita dessas mesmas histórias.

No caso brasileiro, mesmo um século após o início considerado oficial da disciplina histórica no Brasil, isto é, com a fundação do Instituto Histórico e Geográfico Brasileiro (IHGB), no ano de 1838, no Rio de Janeiro, ainda eram os ensaístas aqueles a ousarem buscar definições ou linhas gerais que explicariam o percurso cultural e político que nos havia levado até a década de 1930. Ora, trata-se aqui dos chamados "intérpretes do Brasil", sobremaneira, Caio Prado Júnior, Gilberto Freyre e Sérgio

\footnotetext{
${ }^{1}$ Para uma problematização, neste sentido, ver: ARAUJO (2011, p. 75-92).
} 
Buarque de Hollanda. Ainda era na forma do ensaio que se arriscava dizer o Brasil. ${ }^{2}$ Torna-se oportuno recordar que a então pretensamente moderna Europa instituirá o ensaio como gênero narrativo em sua aurora, com a publicação dos Ensaios, de Michel de Montaigne, em 1580. Cabe, igualmente, mencionar que nessa obra encontra-se um texto intitulado "Sobre os canibais", no qual os indígenas da América portuguesa surpreendem o olhar do francês e denunciam, na sua diferença, a violência da cultura europeia, permitindo que o século XVI crie suas associações com a antiguidade clássica grega (MONTAIGNE, 2010, p. 139-157). A América, como novidade, ajuda a construir a Europa.

$\mathrm{Na}$ América espanhola, de modo geral, o ensaio ocupou lugar privilegiado tanto nos registros escritos que acompanharam os movimentos de conquista quanto aqueles relativos aos processos de independência política, em seus diversos países. Segundo o colombiano Germán Arciniegas, em um rico ensaio intitulado "Nossa América é um ensaio" (1979), antes sequer do nascimento de Montaigne, Cristovão Colombo e Américo Vespúcio já travavam debates por meio de ensaios referentes a assuntos do "Novo Mundo". Além disso, para Arciniegas, o ensaio, como gênero narrativo, é central para aqueles que viveram e vivem a experiência americana: "o ensaio, entre nós, não é um divertimento literário, mas uma reflexão obrigatória diante dos problemas que cada época nos impõe. Esses problemas nos desafiam em termos mais vivos que a nenhum outro povo do mundo" (ARCINIEGAS, 2018, p. 131). O gênero narrativo intitulado "ensaio" seria a forma ideal para o trabalho com a surpresa e a dúvida que marcaria a reelaboração, no espaço e no tempo, deste território: "(...) a América surge no mundo, com sua geografia e seus homens, como um problema. É uma novidade insuspeitada que rompe com as ideias tradicionais. A América, em si mesma, já é um problema, um ensaio de novo mundo, algo que aguça, provoca, desafia a inteligência" (ARCINIEGAS, 2018, p. 129).

De certa maneira, esta foi a perspectiva a partir da qual o continente europeu olhou para a América, mesmo após séculos da conquista territorial: o ponto de vista do exotismo. Essa tópica está demarcada mesmo nas melhores obras que atentam para o continente ou, em particular, para o Brasil. Basta a menção à clássica obra do antropólogo francês Claude Lévi-Strauss, Tristes trópicos (1955), para comprovarmos essa conhecida ideia. Nesse caso, São Paulo seria, para o filósofo francês Célestin Bouglé, interlocutor de Lévi-Strauss, ainda na década de 1930, uma cidade cercada por indígenas, ou seja, a imagem da diferença, do desconhecido e, em alguma medida, do incontrolável (LÉVI-STRAUSS, 1996, p. 45-47). Até mesmo a Antropologia, que se apresenta como a ciência que oferece os métodos ideais para o exame crítico das diferentes culturas, ao lançar seus pressupostos que buscam afastamento do etnocentrismo, segue sujeita aos padrões restritivos do olhar europeu. Tal consideração permite a reflexão que ora se faz pertinente para o argumento que se pretende desenvolver neste ensaio. O que passamos a apreender como modernidade e, em especial, o que acabamos por entender como ciência moderna - e os pressupostos totalizantes associados a esses conceitos - não conduziram a efeitos necessariamente satisfatórios. Em discursos que permanecem apenas parcialmente ligados às disciplinas científicas, como a psicanálise, por exemplo, podemos perceber o reconhecimento do incômodo que a associação entre o moderno, o científico e a ideia de constante

\footnotetext{
2 Para esta perspectiva historiográfica e temporalmente estrita do que viria a ser a cronologia do ensaio histórico e literário no Brasil, remeto ao importante estudo de Fernando Nicolazzi (2011, p. 373-447).
} 
progresso é capaz de produzir. Sigmund Freud, em O mal-estar na civilização (1930), já afirmava que os homens "parecem ter observado que o poder recentemente adquirido sobre o espaço e o tempo, a subjugação das forças da natureza, consecução de um anseio que remonta a milhares de anos, não aumentou a quantidade de satisfação prazerosa que poderiam esperar da vida e não os tornou mais felizes" (FREUD, 2002, p. 39). A resposta de Freud, ao fim e ao cabo, a despeito de seus avanços, era de que havia limites para o retorno que a ciência seria capaz de trazer. Poucas décadas depois, o filósofo francês Michel Foucault demonstraria que aquilo que a ciência, em particular, e a cultura, sem sentido mais amplo, exclui não deixa de existir e, mais, não deixa de ser revelador da própria cultura. São exemplos de exclusão: o sexo, a loucura e o sonho (FOUCAULT, 1996). ${ }^{3}$

Além da psicanálise, as teorias feministas e sua atenção constante à política e à cultura tendem a demonstrar que é da interação crítica com os diferentes discursos de poder que se pode depreender com maior clareza a violência que tais discursos são capazes de impor às diferentes subjetividades humanas e as consequências éticas disso. É patente no pensamento da filósofa feminista Judith Butler tal aspecto:

\begin{abstract}
Faz-se necessário reconsiderar a relação da ética com a crítica social, uma vez que parte do que considero tão difícil de narrar são as normas - de cunho social - que dão origem a minha existência. Elas são, por assim dizer, a condição da minha fala, mas não posso tematizar plenamente essas condições com os termos da minha fala. Sou interrompida por minha própria origem social, e por isso tenho de encontrar um jeito de avaliar quem sou deixando claro que sou da autoria daquilo que me precede e me excede, e que por isso, de maneira nenhuma, me exime de ter de relatar a mim mesma. Mas significa que se me posiciono como se pudesse reconstruir as normas pelas quais se instaura e se sustenta minha condição de sujeito, então recuso a própria desorientação e interrupção da minha narrativa implicada pela dimensão social dessas normas (BUTLER, 2017, p. 107).
\end{abstract}

Este momento introdutório faz-se necessário na medida em que é fundamental situar a proposta de uma História dos Sertões, tal como ora se concebe, no âmbito dos movimentos teóricos e políticos mais amplos dos estudos de gênero, dos estudos subalternos e das teorias do sul-global, sem desconsiderar as críticas feministas e o diálogo com a psicanálise contemporânea. Trata-se de operar a partir de territorialidades e subjetividades outras, que visam, entre outras demandas urgentes, buscar novas escalas que denunciem os silenciamentos e as supostas certezas sobre as diferenças e similitudes nacionais americanas. Não parece pertinente à proposta de se escrever diferentes histórias sertanejas sem que antes se redimensione o diálogo da epistemologia da história com a filosofia política, com a história social e, ainda, com os avanços já estabelecidos dos feminismos e da ética psicanalítica. Com a afirmação dessa etapa de contrapontos necessários entre o que simplificamos com o uso de categorias e identidades mais amplas (mas nem de longe resolvem as injustiças com relação às diferenças), pode-se retornar ao diálogo mais estabelecido nas Humanidades, à proposta de uma História dos Sertões e à companhia de um projeto de construção propriamente humano de sujeitos históricos como contribuição decorrente desses esforços.

\footnotetext{
${ }^{3}$ Remeto, ainda, para uma reflexão contemporânea acerca das exclusões que o discurso da modernidade produziu a partir das ideias de razão e de ciência, escrita pelo psicanalista Christian Dunker (2017, p. 9-41).
} 


\section{Sertões: o outro lado do paraíso}

A forma do ensaio, como descrita por diversos teóricos, transita entre a história e a literatura, a ciência e a arte. De certo modo, tal apreciação acompanha, conscientemente, o argumento que se quer explorar neste texto. Propor uma área de estudos implica, necessariamente, em retomar os debates epistemológicos e políticos mais amplos que acompanham os campos já consolidados dos saberes e, principalmente, justificar as especificidades da postulante nova frente de exames. De imediato, importa destacar a aproximação entre a proposta de uma História dos Sertões como área específica e os estudos pós-coloniais. A perspectiva que tenta tornar mais complexa as relações de poder em diferentes espacialidades e, ao mesmo tempo, busca expor os conflitos que a história do colonialismo de matriz europeia tende a encobrir, em parte explica a decorrência da referida aproximação. A cientista social australiana Rawyen Connell torna mais clara a afirmação: “(...) a análise do colonialismo, portanto, leva a problemas sobre o próprio conhecimento, pois estas análises geralmente não surgem e não estão confortavelmente contidas dentro das estruturas de conhecimento da metrópole global" (CONNELL, 2017, p. 97, grifos da autora). O ponto de partida de qualquer projeto intelectual que se coadune às discussões pós-coloniais traduz-se em indagar acerca do conhecimento, dos métodos e conceitos incorporados à proposta, no sentido de provocar a adequada separação entre a experiência colonial e a ideia de uma epistemologia sustentada em princípios de autonomia e paridade. Dito de outra forma, o argumento para a teoria do Sul não é principalmente sobre proposições diferentes, mas sobre práticas de conhecimento diferentes" (CONNELL, 2017, p. 103).

Nesse horizonte, é importante ressaltar que a combinação entre o que propõem os estudos pós-coloniais e subalternos, as teorias feministas e as contribuições da psicanálise, preservadas suas agendas e diferenças, não corresponde, evidentemente, a uma ruptura com os projetos metropolitanos, mas sim à sustentação dos conflitos que sobrecarregam as historiografias periféricas.

O sociólogo peruano Aníbal Quijano prestou destacada contribuição ao demonstrar os efeitos que o eurocentrismo e a chamada "colonialidade do poder" exercem sobre o capitalismo em operação na América do Sul ao relacionar o conceito de raça à divisão do trabalho nesta espacialidade (QUIJANO, 2005). A conclusão mais enfática trazida por Quijano, ao menos para esta leitura, é aquela que diz respeito ao papel que a construção mental "raça" teve: autorizar relações de dominação no interior das experiências americanas, mas também nas trocas com a Europa, entendida como metrópole global. Ao levantar a mencionada constatação, torna-se mais nítida a relevância da América para a constituição da Europa como unidade totalizante e de sua suposta construção individual: a modernidade.

Ultrapassaria os limites desta pesquisa aprofundar o debate relacionado às dimensões mais diretamente ligadas ao capitalismo como modo de produção e sistema mundial, embora seja crucial considerar, de maneira sistemática, a preponderância da categoria "classe" em qualquer leitura que operacionalize as categorias de "gênero" e "raça", de forma crítica. Por ora, cabe retomar a problemática da disciplina histórica e, a partir dela, defender a produção do conhecimento como uma forma de trabalho (CONNELL, 2017, p. 91). A área de história de historiografia, no Brasil, tem se deslocado no sentido de compor o diálogo travado nas últimas décadas a partir das experiências dos estudos subalternos e pós-coloniais. A reflexão de historiadores brasileiros tem encontrado espaço de interlocução em importantes canais internacionais de trocas 
intelectuais, sejam estes meios os de publicações ou de eventos acadêmicos.

O projeto de uma História dos Sertões como área de concentração particular advém, em parte, das sugestões de Mateus Henrique de Faria Pereira, Pedro Afonso Cristovão dos Santos e Thiago Lima Nicodemo, em artigo publicado recentemente (2017). No que tange à história da historiografia produzida por brasileiros, os historiadores em questão destacam a oportunidade que o diálogo internacional mais amplo proporcionado pelos estudos subalternos e pós-coloniais pode favorecer a "ampliação de um repertório de temas de pesquisa, ferramentas conceituais e perguntas que se abrem quando refletimos acerca do enraizamento eurocêntrico e etnocêntrico das nossas representações históricas" (SANTOS; NICODEMO; PEREIRA, 2017, p. 163). Os historiadores trazem no artigo, além dessa indicação, o convite à reflexão crítica relacionada à perspectiva global na escrita da história, retomando a extensa discussão atinente aos limites da historiografia conduzida sob à égide do "nacional". 4 Pode-se destacar, por fim, que o artigo assinado pelos três historiadores, ao analisar importantes textos de nomes ligados aos estudos subalternos, como os indianos Sanjay Subrahmanyam e Dipesh Chakrabarty, traz a seguinte indagação: "nessa perspectiva, a história produzida com bases nos pressupostos estabelecidos historicamente na Europa estaria condenada ao eurocentrismo? (SANTOS; NICODEMO; PEREIRA, 2017, p. 178).

O objetivo deste ensaio não consiste em responder à importante questão supracitada. A proposta é mais modesta, mas inspira-se neste debate mais amplo que, justamente por sua abrangência, é capaz de sustentar a proposta aqui apresentada. De acordo com o que se depreende dos resultados trazidos no artigo acima, podemos considerar, a princípio, que os recursos disciplinares impõem, ao menos parcialmente, incontornável eurocentrismo, posto que as disciplinas científicas modernas foram concebidas e tornadas consenso "universal" desde a Europa. Entretanto, a operacionalização de conceitos a partir uma revisão crítica destes configura-se como entrada possível à área de História dos Sertões, tal qual buscamos minimamente circunscrever nesta etapa inicial da pesquisa que estimulou este ensaio. O mapeamento dos significados atribuídos à categoria "sertão", desde o início da conquista e exploração do território americano por portugueses (e mesmo de outras espacialidades como na África e na Ásia) encontra-se disperso e, em desdobramentos futuros será tratado. Para esta ocasião, a especificidade a ser exposta, com o escopo de delinear a área de História dos Sertões, é aquela que se volta para a construção de um conjunto de referências que auxiliem em suas definições. Na próxima seção, uma tentativa será apresentada.

\section{Para outras histórias dos sertões}

O argumento principal descrito aponta para o fato de que os sertões foram, em geral, tematizados pelas diferentes historiografias, quase que exclusivamente pela ótica dos recortes espaciais (o nacional, o regional etc.). O conhecido artigo de Janaína Amado (1995) afirma tal inferência. Esse sertão cartográfico, geográfico, foi, pouco a pouco, complementado por camadas históricas que alteraram essa conotação primária e mais geral. Apesar disso, interessa destacar que mesmo os significados mais ligados às territorialidades carregaram, ao longo do tempo, elementos e dimensões que

\footnotetext{
${ }^{4}$ Neste sentido, aponto para o livro recentemente publicado, sob organização de Erick Assis de Araújo e João Júlio Gomes dos Santos Júnior (2018) intitulado História urbana e global.
} 
colaboraram para a projeção dos mundos europeus sobre o espaço americano, alimentando, inclusive projetos de poder voltados para conceitos de identidades úteis à dominação. A ideia de uma História dos Sertões, assim, sugere que avancemos, por exemplo, a partir das contribuições dos estudos da historiadora Maria Elisa Mäder (2008). Mäder reflete sobre como as representações espaciais do século XIX são reveladoras de uma historiografia construída como imagem e semelhança da Europa.

\begin{abstract}
Minha hipótese é que a exaltação da natureza nas Américas pode ter substituído o papel que a tradição e a herança desempenhariam no processo de legitimação dessas identidades. Os construtores das novas nações americanas não podiam e não queriam, neste momento, vangloriar-se de seu passado, fosse o passado colonial dos últimos séculos - identificado ao obscurantismo, ao atraso, o oposto do progresso e das luzes da época, fosse o passado mais remoto das dinastias indígenas, ambos inconciliáveis com as novas ideias de humanismo, tolerância e liberdade civil. Por isso, vão vangloria-se e buscar legitimidade não em uma herança histórica ou em uma antiguidade mítica, mas no vigor fecundo da natureza circundante, vigorosa, exuberante, que parecia prometer generosamente, ou mesmo garantir um desenvolvimento ilimitado (MÄDER, 2008, p. 263).
\end{abstract}

Ligada à metáfora de "paraíso terrestre", as terras americanas atravessariam os séculos com uma imagem unidimensional descrita como natural, campo vazio de cultura, aberto à conquista e desbravamento. Como demonstra a historiadora, seja no caso da Argentina, com os espaços denominados "pampas" ocupados pelos "gaúchos", seja no caso do Brasil, e dos "sertões" e seus "sertanejos", a América era formulada como um imenso vazio a ser preenchido pelas leis e normas europeias. Aos pequenos centros "civilizados" situados em regiões litorâneas ou portuárias correspondiam imensos territórios de "barbárie", projeção anacrônica de explicações históricas que povos apenas muito tardiamente se reconheceriam como europeus dariam para construir suas origens. Mäder explica com significativa clareza os sertões concebidos no século XIX a partir do olhar exterior. Esse é um ponto de partida para justificar investigações que partam dos sertões contemporâneos, capazes de promover outras formas de relações com os discursos de saber e poder.

Em semelhante direção, pode-se defender a validade de investigações que alimentem um olhar mais abrangente dos espaços ditos pela Europa, aproximando leituras sobre a mencionada história argentina, por exemplo. Leandro José Nunes seguiu na mesma direção e, em sua análise de Facundo, clássico texto de autoria de Domingo F. Sarmiento (1851), demonstrou como as categorias "civilização" e "barbárie" presentes no documento oitocentista participaram de forma determinante em lutas políticas no período e também posteriormente, nas diversas reescritas historiográficas (NUNES, 2011). Para o caso da América do Norte, o historiador Arthur Lima de Ávila examinou o os estudos sobre o Oeste dos Estados Unidos e a perspectiva de uma história da fronteira, argumento central para a composição das identidades territorial e política do país (ÁVILA, 2009). Como demonstra Ávila, a construção nacional dos Estados Unidos dependeu da ideia de uma fronteira oeste em constante movimento, sempre a avançar rumo à conquista de territórios "vazios", abertos à conquista e ocupação.

A antropóloga Candice Vidal de Souza, no livro A pátria geográfica, explorou a mesma ideia de sertões apreendidos como fronteiras em movimento. Segundo Souza, essa apropriação acerca dos sertões foi construída em termos de conhecimento científico, embora depois tenha servido para alimentar o campo político discursivo sobre 
a nação. Esse foi o caminho percorrido para que a associação entre sertão e brasilidade se consolidasse (SOUZA, 1997, p. 135). Ainda, a antropóloga estabelece uma interessante relação entre a Amazônia entendida como "conquista" portuguesa, na medida em que a floresta se apresenta como barreira natural às terras espanholas, enquanto que os sertões (posteriormente denominados como do Centro-Oeste ou do Nordeste) entendidos como "brasileiros", no sentido em que resguardariam o cerne da nacionalidade, como se veria em Euclides da Cunha e Capistrano de Abreu (SOUZA, 1997, p. 140). Paradoxalmente, a nacionalidade brasileira apresentar-se-ia incompleta, em função da fragmentação de uma identidade dispersa nos sertões, ao mesmo tempo em que a geografia faria mais pela nação brasileira que a história, na medida em que apenas o domínio do território traria a definição do caráter nacional.

O controle exercido sobre os sertões ao longo do tempo foi analisado em diversas frentes. Contudo, destacam-se algumas leituras que colaboram na organização deste breve mapeamento inicial. A primeira entrada possível é, sem dúvida, o olhar cientificista. Na senda aberta pela força da obra de Euclides da Cunha, Os Sertões, publicada em 1902, a historiadora Luciana Murari explorou como o discurso cientificista, a despeito de suas contradições, ou mesmo em razão delas, desvelou uma nacionalidade somente possível como ficção, dadas as distâncias entre o que impunha o olhar europeu e a realidade brasileira e entre as diversas camadas sociais separadas entre o litoral e Canudos (MURARI, 2007).

A ficção como construtora da realidade também foi o mote utilizado pelo historiador Eduardo Wright Cardoso na aproximação com a obra de Euclides da Cunha. Cardoso opta por contribuir a partir da análise do uso do recurso narrativo da cor local para verificar como, em Os Sertões, são construídas imagens da nacionalidade. Para o historiador, todavia, os usos desse recurso vão além, e acabam por alimentar a própria narrativa, em seu potencial de representação. Os resultados desses usos são tão significativos que, na opinião do autor, a vasta fortuna crítica da obra, em certa medida, reproduzirá as mesmas imagens. Ideia comum a todos os projetos nacionais dos séculos XIX e XX, a criação de imagens sobre as nações é esforço de letrados e intelectuais que, pelo mundo do texto, pretendiam lançar sentidos particulares ao projeto "universal" das nações. A apropriação do recurso à cor local, na leitura trazida por Cardoso, ajudaria a compreender a força visual de sua prosa, muitas vezes reproduzida por seus críticos (CARDOSO, 2018).

A produção sobre os sertões e vinculada à História Social ou, em sentido mais geral, ao chamado pensamento social brasileiro, merece ser recuperada quando tomamos como marco vertical a publicação de Os Sertões, talvez a obra que de fato organiza a crítica que a proposta de uma História dos Sertões pretende oferecer. Perguntar-se sobre os motivos que levaram a força da obra de Cunha é o que faz Regina Abreu, no livro O enigma de Os Sertões (1997). Abreu perguntou-se sobre "quem" diz os sertões, quem os transforma em território discursivo. $O$ ato de nomear, gesto de poder, criador de hierarquias, é um dos enfoques da autora. Lucia Lippi Oliveira, por sua vez, fará percurso semelhante, porém mais geral, na procura por uma interpretação do Oeste brasileiro. A pesquisadora dedicou-se a compreender como as ideias de sertão e de fronteira alimentaram o pensamento social e como, na literatura, na história, no jornalismo e demais áreas do saber letrado e intelectual os sertões foram tematizados e ofereceram ao Estado instrumentos e narrativas úteis à sua manutenção (OLIVEIRA, 2015).

Em outras coordenadas geográficas, bem como em diferentes histórias, o 
percurso dos sertões do Nordeste e do Centro-Oeste, em certo recorte, monopolizaram as atenções dos estudiosos. No primeiro caso, o historiador Durval Muniz de Albuquerque Junior, em seu livro A invenção do nordeste e outras artes (2002), examinou como a construção sulista que erigiu a ideia de nordeste, com a participação das elites dessa região, para ser devidamente consolidada, exigiu a vinculação direta de algumas ideias (seca, pobreza, folclore), particularmente a ideia de "sertão". O nordeste, tal qual o Brasil, define-se, em parte, pelo potencial representativo dessa categoria. Os sertões mato-grossenses também foram espaços estigmatizados por um conjunto limitado de categorias que, em síntese, apenas reproduziam preconceitos sobre as populações que lá vivem. Esta foi a motivação para que o historiador Eduardo de Melo Salgueiro viesse a encaminhar um estudo sustentado por fontes da imprensa que pretendiam verificar como a classe política do estado do Mato Grosso, em meados do século XX, tentou dirimir tal discurso, reelaborando as descrições pejorativas ainda ligadas ao bandeirantismo (SALGUEIRO, 2017).

Por meio deste breve balanço, ainda incipiente, porém inspirador, pode-se apontar caminhos para outras histórias dos sertões, talvez menos dependentes de categorias distantes das realidades sertanejas nacionais e estrangeiras, mais críticas em relação às conotações coloniais e, sobremaneira, mais variadas. Tratou-se, até aqui, menos de um balanço exaustivo, mas de chaves de leitura abertas e que se posicionam, no projeto aqui exposto, como meios de superação de uma história desmedidamente única e condicionada por uma concepção de disciplina histórica também restrita.

\section{Considerações finais}

Este ensaio pretendeu lançar algumas proposições, com o objetivo de alimentar as possibilidades de uma História dos Sertões como área específica de estudos, no Brasil. Longe de ser uma proposição sustentada por mais um recorte espacial, o projeto consiste em partir de um exame do conceito de sertão, avançar rumo ao estabelecimento de um conjunto de referências básicas que sustente esse saber e, sobretudo, operar com a categoria em questão com vistas a fortalecer a escrita de histórias alternativas às categorias tradicionalmente apropriadas pelos estudos de história e historiografia brasileiros e internacionais.

Partindo dos marcos cronológicos que o conhecimento europeu costumeiramente ofereceu ao saber histórico do Brasil, buscou-se estabelecer os critérios mais gerais e incontornáveis para que, desde o século XIX, a história brasileira e, em sentido mais amplo, americana, ganhasse seus sentidos primários. A instabilidade inerente de tais referentes foi problematizada pela reflexão que tomava a América como um "grande sertão" ao olhar do conquistador. Nem mesmo com o desenvolvimento da disciplina antropológica, ao longo do século XX, os incômodos e as lacunas dessa visão exótica foram plenamente superados.

A escolha assumida como pressuposto ao longo deste ensaio foi tomar os debates constituídos pelos estudos subalternos, estudos pós-coloniais, pensamentos feministas e psicanálise como instrumentos teóricos e políticos, disciplinares e éticos, para alimentar uma agenda de temas, mas, principalmente, de problemas que sustentem uma História dos Sertões. Interessado no intenso diálogo com a história da historiografia tal como é pensada hoje no Brasil, o projeto de uma História dos Sertões pretende contribuir com as problemáticas contemporâneas sobre as relações entre natureza e cultura e também sobre a complexidade do pensamento a respeito de novas 
espacialidades. Entretanto, este projeto pretende estimular a produção de uma historiografia sobre os sertões e, mais ainda, desde os sertões. Trata-se de uma historiografia que intenta se ocupar do problema deixado em aberto pelos limites eurocêntricos da modernidade e da ciência em seus padrões europeus, qual sejam, aqueles que entendem sujeitos históricos como portadores de subjetividades, que fazem parte da política e também da produção de saberes. A proposta de uma História dos Sertões como área de concentração específica e, ao mesmo tempo, abrangente (posto que se mostra aberta às diferentes espacialidades alternativas existentes no mundo), começa pelo mapeamento de leituras possíveis, já realizadas, mas se encaminha para histórias alternativas, ainda não narradas.

\section{Referências}

ABREU, Capistrano de. Capítulos de história colonial, 1500-1800. 7. ed. Belo Horizonte: Itatiaia; São Paulo: Publifolha, 2000.

ABREU, Regina. O enigma de Os Sertões. Rio de Janeiro: Funarte: Rocco, 1998.

ALBUQUERQUE JÚNIOR, Durval Muniz de. A invenção do Nordeste e outras artes. 5. ed. São Paulo: Cortez, 2011.

AMADO, Janaína. "Região, sertão, nação". Estudos Históricos, v. 8, n. 15, p. 145-52, 1995.

ARAÚJO, Erick Assis de; SANTOS JÚNIOR, João Júlio Gomes dos (Orgs.). História urbana e global: novas tendências e abordagens. Fortaleza: EdUECE, 2018.

ARAUJO, Valdei Lopes de. Cairu e a emergência da consciência historiográfica no Brasil (1808-1830). In: NEVES, Lúcia Maria Bastos Pereira das et al. (Orgs.). Estudos de historiografia brasileira. Rio de Janeiro: Editora FGV, 2011, p. 75-92.

ARENDT, Hannah. Entre o passado e o futuro. São Paulo: Perspectiva, 2003, p. 110121.

ARCINIEGAS, Gérman. Nossa América é um ensaio. In: PIRES, Paulo Roberto (Org.). Doze ensaios sobre o ensaio: antologia serrote. São Paulo: IMS, 2018, p. 128-142.

ARRUDA, Gilmar. Cidades e sertões: entre a história e a memória. Bauru, SP: EDUSC, 2000.

ÁVILA, Arthur Lima de. Da História da Fronteira à História do Oeste: crise e fragmentação na Western History norte-americana no século XX. História Unisinos, v. 13, p. 84-95, 2009.

BALLESTRIN, Luciana. América Latina e o giro decolonial. Revista Brasileira de Ciência Política, v. 2, p. 89-117, 2013.

BUTLER, Judith. Relatar a si mesmo: crítica da violência ética. Belo Horizonte: Autêntica Editora, 2017.

CARDOSO, Eduardo Wright. Euclides da Cunha e a cor local: a pintura da história de Canudos. ANOS 90 (online) (Porto Alegre), v. 25, p. 279-304, 2018.

CHAKRABARTY, Dipesh. Provincializing Europe: postcolonial thought and historical 
difference. Princeton, New Jersey: Princeton University Press, 2000.

CONNELL, Rawyen. Usando a teoria do sul: descolonizando o pensamento social na teoria, na pesquisa e na prática. Epistemologias do Sul, Foz do Iguaçu/PR, 1 (1), p. 87109, 2017.

CUNHA, Euclydes da. Os sertões: Campanha de Canudos. 39. Ed. Rio de Janeiro: Livraria Francisco Alves Editora; Publifolha, 2000.

DUNKER, Christian (Org.). Ética e pós-verdade. Porto Alegre: Dublinense, 2017.

FABIAN, Johannes. O Tempo e o Outro: como a Antropologia estabelece seu objeto. Petrópolis, RJ: Vozes, 2013.

FOUCAULT, Michel. A ordem do discurso. São Paulo: Edições Loyola, 1996.

FREUD, Sigmund. O mal-estar na civilização. Rio de Janeiro: Imago Ed., 2002.

GUIMARÃES, Manoel Luiz Salgado. A cultura histórica oitocentista: a constituição de uma memória disciplinar. In: PESAVENTO, Sandra Jatahy (Org.). História Cultural: experiências de pesquisa. Porto Alegre: Editora da UFRGS, 2003, p. 9-24.

HARTOG, François. Regimes de historicidade: presentismo e experiências do tempo. Belo Horizonte: Autêntica Editora, 2013, p. 37-41.

LÉVI-STRAUSS, Claude. Tristes trópicos. São Paulo: Companhia das Letras, 1996.

MÄDER, Maria Elisa. Civilização, barbárie e as representações espaciais da nação nas Américas no século XIX. História Unisinos, São Leopoldo, 12(3), Setembro/Dezembro, p. 262-270, 2008.

MONTAIGNE, Michel de. Os ensaios: uma seleção. SCHEECH, M. A. (Org.). Tradução: Rosa Ferreira d'Aguiar. São Paulo: Companhia das Letras, 2010.

MURARI, Luciana. Brasil, ficção geográfica: ciência e nacionalidade no país d'Os Sertões. São Paulo: Annablume, Belo Horizonte: Fapemig, 2007.

NEVES, Erivaldo Fagundes. Crônica, memória e história: formação historiográfica dos sertões da Bahia. Feira de Santana, BA: UEFS Editora, 2016.

NICOLAZZI, Fernando. Um estilo de história: a viagem, a memória, o ensaio: sobre Casa-grande e senzala e a representação do passado. São Paulo: Editora Unesp, 2011.

NUNES, Leandro José. Facundo: civilização e barbárie: uma leitura da sociedade argentina no século XIX. História e Perspectivas, Uberlândia (45), p. 83-104, jul./dez. 2011.

OLIVEIRA, Valter Gomes Santos de. "Vivemos identificados com a civilização, dentro da civilização": autoimagens urbanas nos sertões da Bahia. Revista Brasileira de História, São Paulo: v. 35, n. 69, p. 301-318, 2015.

QUIJANO, Anibal. Colonialidade do poder, Eurocentrismo e América Latina. Buenos Aires, 2005.2 Disponível português em: http://biblioteca.clacso.edu.ar/clacso/sursur/20100624103322/12_Quijano.pdf

SALGUEIRO, Eduardo de Melo. Fugindo do estigma: visões sobre Mato Grosso nas 
páginas da Série Realidade Brasileira e da revista Brasil-Oeste. ANOS 90 (online) (Porto Alegre), v. 24, p. 269-300, 2017.

SANTOS, Pedro A. C. dos; NICODEMO, Thiago e PEREIRA, Mateus H. de Faria. Historiografias periféricas em perspectiva global ou transnacional: o eurocentrismo em questão. Estudos Históricos, v. 30, n. 60, p. 161-186, 2016.

SCHWARCZ, Lilia Moritz. O espetáculo das raças: cientistas, instituições e questão racial no Brasil (1870-1930). São Paulo: Companhia das Letras, 1993. SETH, Sanjay. Razão ou raciocínio? Clio ou Shiva? História da Historiografia, n. 11, abril, p. 173-189, 2013.

SILVA, Sandro Dutra e; SÁ, Dominichi Miranda de; SÁ, Magali Romero (Orgs.). Vastos sertões: história e natureza na ciência e na literatura. 1. ed. Rio de Janeiro: Mauad X, 2015.

SOUZA, Candice Vidal e. A pátria geográfica: sertão e litoral no pensamento social brasileiro. 2.ed. Goiânia: Editora UFG, 2015.

\section{Notas de autoria}

Evandro dos Santos é doutor em História pela Universidade Federal do Rio Grande do Sul. Professor adjunto de Teoria e Metodologia da História no Departamento de História do CERES e do Programa de Pós-Graduação em História dos Sertões do CERES da Universidade Federal do Rio Grande do Norte (CERES-UFRN). E-mail: evansantos.hist@gmail.com.

\section{Como citar esse artigo de acordo com as normas da revista}

SANTOS, Evandro dos. Ensaio sobre diversidade historiográfica: como escrever (e reconhecer) histórias dos sertões a partir de novas e "velhas" epistemologias. Sæculum - Revista de História, v. 24, n 41, p. 441-452, 2019.

\section{Contribuição de autoria}

Não se aplica.

\section{Consentimento de uso de imagem}

Não se aplica.

\section{Aprovação de comitê de ética em pesquisa}

Não se aplica.

\section{Licença de uso}

Este artigo está licenciado sob a Licença Creative Commons CC-BY. Com essa licença você pode compartilhar, adaptar, criar para qualquer fim, desde que atribua a autoria da obra.

\section{Histórico}

Recebido em 26/08/2019.

Aprovado em 10/10/2019. 